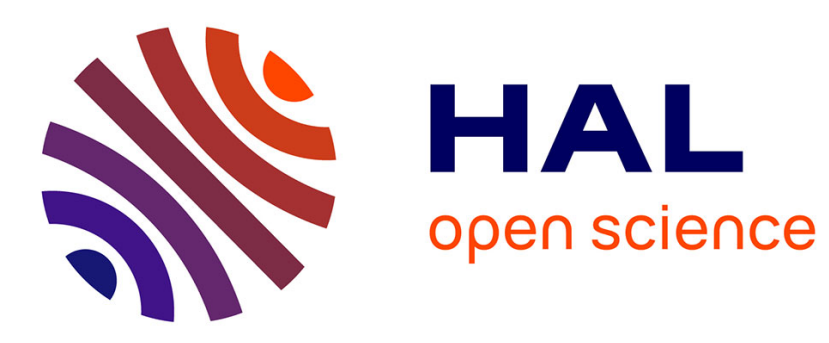

\title{
Paleoclimatic reconstruction using Mutual Climatic Range on terrestrial mollusks.
}

Olivier Moine, Denis-Didier Rousseau, Dominique Jolly, Marc Vianey-Liaud

\section{To cite this version:}

Olivier Moine, Denis-Didier Rousseau, Dominique Jolly, Marc Vianey-Liaud. Paleoclimatic reconstruction using Mutual Climatic Range on terrestrial mollusks.. Quaternary Research, 2002, 57, pp.162-172. 10.1006/qres.2001.2286 . hal-01208190

\section{HAL Id: hal-01208190 \\ https://hal.science/hal-01208190}

Submitted on 2 Oct 2015

HAL is a multi-disciplinary open access archive for the deposit and dissemination of scientific research documents, whether they are published or not. The documents may come from teaching and research institutions in France or abroad, or from public or private research centers.
L'archive ouverte pluridisciplinaire HAL, est destinée au dépôt et à la diffusion de documents scientifiques de niveau recherche, publiés ou non, émanant des établissements d'enseignement et de recherche français ou étrangers, des laboratoires publics ou privés. 
Olivier Moine

Paléoenvironnements \& Palynologie, Institut des Sciences de l’Evolution (UMR CNRS 5554), Université Montpellier II, case 61, place E. Bataillon, 34095 Montpellier Cedex 5, France

\section{Denis-Didier Rousseau}

Paléoenvironnements \& Palynologie, Institut des Sciences de l'Evolution (UMR CNRS 5554), Université Montpellier II, case 61, place E. Bataillon, 34095 Montpellier Cedex 5, France and Lamont-Doherty Earth Observatory of Columbia University, Palisades, New York 10964

\section{Dominique Jolly}

Paléoenvironnements \& Palynologie, Institut des Sciences de l’Evolution (UMR CNRS 5554), Université Montpellier II, case 61, place E. Bataillon, 34095 Montpellier Cedex 5, France

\section{Marc Vianey-Liaud}

Génétique et Environnement, Institut des Sciences de l'Evolution (UMR CNRS 5554), Université Montpellier II, case 64, place E. Bataillon, 34095 Montpellier Cedex 5, France

\section{Running head: Mutual Climatic Range on Quaternary mollusk}

\section{Corresponding author :}

Address : Moine Olivier, Paléoenvironnements \& Palynologie, Institut des Sciences de l’Evolution (UMR CNRS 5554), Université Montpellier II, case 61, place E. Bataillon, 34095 Montpellier Cedex 5, France

Email : omoine@isem.univ-montp2.fr

Tel: 33 4.67.14.39.25

Fax : 33 4.67.04.20.32 


\title{
Paleoclimatic reconstruction using Mutual Climatic
}

\section{Range on terrestrial mollusks.}

\begin{abstract}
Terrestrial mollusks, easily identified in Quaternary sediments, represent a reliable tool for quantitative estimates of environmental parameters. Our study, comparing the species distribution with meteorological parameters in Europe, shows that mean temperature of the coldest month and annual thermal magnitude are the most important forcing parameters. This survey allows us to adapt the Mutual Climatic Range (MCR) method to terrestrial mollusk assemblages following two main steps. A set of assemblages from different European regions (northern Norway to southern France) is used to apply the method on present day mollusks. The reconstructed values describe the latitudinal temperature gradient prevailing over Europe. However, the comparison between the reconstructed and the measured values indicates a shift, similar to that observed, with the same method applied on beetle assemblages. Thus, estimates must be calculated after tuning the reconstruction with the observations. The results from the modern mollusk assemblages indicate that the MCR method can be safely applied to reconstruct temperatures from terrestrial mollusk assemblages in any worldwide Quaternary sequence. A trial application is made on Late Pleistocene assemblages from Achenheim (Alsace, France).
\end{abstract}

Key words: terrestrial mollusks; Mutual Climatic Range; Europe; Quaternary; continental paleoclimatology; quantitative temperature estimates 


\section{INTRODUCTION}

Temperature and moisture are the main factors that constrain the physiology and life cycle of terrestrial mollusks. Each species has a thermal interval controlling its activity (Pelseneer, 1935; Dainton, 1954; Franc, 1968b; Sacchi and Testard, 1971; Chevallier, 1982; Watabe, 1983; Rollo, 1991), its growth (Pelseneer, 1935; Uminski, 1975; Chevallier, 1982), its reproduction (Pelseneer, 1935; Bouillon, 1956; Franc, 1968b; Gomot et al., 1986; Gomot and Griffond, 1993), and its physiological functions (Pelseneer, 1935; Blazka, 1953; Langley, 1979; Armitage and Stinson, 1980; Biannic et al., 1995). Therefore these different thermal ranges determine specific wider thermal domains of life, outside ranges of which they cannot survive. In comparison, moisture or precipitation cannot be determined so reliably. Indeed, experiments considering the influence of moisture variations on mollusks do not yield results as precise as for temperature (Pelseneer, 1935; Blazka, 1953; Chevallier, 1982; Phifer and Prior, 1985; Rollo, 1991; Biannic et al., 1995). Thus, as the link between moisture and precipitation is not obvious, any reconstruction of moisture and precipitation using mollusks evidence appears presently difficult.

Terrestrial mollusks are indices of both vegetation type and climate, permitting them to be grouped in ecological clusters (Lozek, 1964; Puisségur, 1976). They are highly sensitive to environmental variation and provide reliable record of their biotope (Light and Killeen, 1996). The time response of malacofaunas to environmental changes, especially biome disappearance, is less than fifty years (Light and Killeen, 1996), indicating that modern distributions are in equilibrium with present environments. Mollusk shells are well-preserved in Quaternary sediments, particularly in loess deposits, and can be identified at the species level using their form and ornamentation (Lozek, 1964; Puisségur, 1976), even though they are often broken (mainly large species). Consequently, biological qualitative information (i.e. species recognition) is generally preserved after the burial of the individuals. In addition, an 
important proportion of the quantitative information, lost by breakage, can be recovered by applying numerical corrections on identified and counted fragments (Puisségur, 1976). These observations led Lozek (1964) to consider that the ecological tolerances of each species are maintained through the Quaternary (Lozek, 1964). Therefore, since terrestrial mollusks record ecological and climatic variations, they can provide an excellent proxy from which to extract palaeoenvironmental information.

In parallel to new biological indicators used since the initial development of transfer functions on marine microfaunas (Imbrie and Kipp, 1971), several methods have been determined to estimate past climate and environmental parameters. The differences between these methods depend on the characteristics of the material and the modes of calculation (Guiot, 1994).

The relationship between terrestrial mollusks and climate is achieved through having a statistically valid number of samples from a present area large enough to be representative of as many different types of assemblages and climates as possible. Sometimes, however, a determined area does not include the complete range of assemblage categories identified in a fossil sequence, and thus non-analogues appear. In biological datasets of this type, two modes of calculation can be used: extrapolation and interpolation.

Extrapolation uses methods allowing the reconstruction of parameter values outside a reference dataset (Fritts et al., 1971; Webb III and Bryson, 1972; Guiot, 1986). However, the dataset values define a domain inside which a relationship between a proxy and a climate parameter can be established. Thus, as the relationship is not always valid outside this domain, these methods are not recommended. Furthermore, in most of the cases, there are no means to confirm the calculated estimates (Guiot, 1994). Interpolation methods by comparison constrain the reconstructions only in the domain of the reference dataset values. These methods have been applied to different biological proxies: pollen (Overpeck et al., 
1985; Guiot, 1987; Huntley and Prentice, 1988), lacustrine ostracods (Mourguiart et al., 1998), lacustrine diatoms (Gasse and Tekaia, 1983), rodents (Montuire, 1999), and mollusks (Rousseau, 1991). But even in these cases, problems of non-linear response by the fauna or flora to a determined climatic parameter may occur inside the domain of the reference dataset. This prevents reconstruction beyond intrinsic thresholds if no improvements are realized (Waelbroeck et al., 1998). The methods used vary according to the sensitivity of the organisms to the environment and the time interval investigated.

From terrestrial mollusks assemblages, temperature and precipitation reconstructions have previously been calculated using the analogues method (Rousseau, 1991; Rousseau et al., 1994; Rousseau et al., 1998a). However the present analogue assemblages are located only in Western Europe, and the use of this method is strictly restricted to this area. Furthermore, the possibility of non-analogous assemblages cannot be excluded. Such assemblages yield only approximate reconstructions. Otherwise, this method has already been successfully adapted and applied to different organisms such as insects (Atkinson et al., 1987; Elias, 2000), pollen (Peyron, 1998) and rodents, following a similar principle called the Hokr method (Chaline and Brochet, 1989). By taking into account these methodological restrictions, we decided to test the use of the Mutual Climatic Range method (MCR) on mollusk assemblages, which seems possible to apply throughout the range of terrestrial mollusks.

\section{MATERIAL}

\section{Modern data}

The MCR method employs the modern geographic distributions of the different Pulmonate and Prosobranch species identified in the fossil assemblages used. Concerning Europe, these were published in the malacological atlas of Kerney et al. (1983). 
The corresponding European meteorological dataset has been extracted from a global database (Leemans and Cramer, 1991). This includes 1735 stations providing minimal and maximal mean monthly temperatures for Europe between $72^{\circ} \mathrm{N}$ and $41^{\circ} \mathrm{N}$, and between $11^{\circ} \mathrm{W}$ and $33^{\circ} \mathrm{E}$ (Fig. 1). The values of these parameters, linked with the species geographic distributions, allows the definition of Specific Climatic Ranges (SCR) (Atkinson et al., 1986). Furthermore, as malacological distributions are based on modern samples (Kerney et al., 1983), and climatic data on records obtained between 1941 and 1960 (Leemans and Cramer, 1991), we consider that the published malacological distributions are in equilibrium with the climatic data used. Indeed, numerous cold resistant species leave presently in Scandinavia. Such pattern implies that the colonization by the mollusks of this formerly glaciated area during the Holocene was rapid. The northward extension of the geographical distributions of determined species, related to the present interglacial conditions, can then be assumed as completed in this area. However, if present climatic conditions related to global warming continues to extend northward the geographical distributions, Tmin and Tmax estimates will then be overestimated.

The MCR method was calibrated using modern mollusk samples taken in six different regions distributed parallel to the present N-S European thermal gradient (Fig. 2). These regions are: Karasjakk (Norway) (Andersen and Halvorsen, 1984), Abisko (Sweden) (Nilsson, 1968; Nilsson, 1987), Dovrefjell (Norway) (Pokryszko, 1989), Périgord (France) (Limondin, 1990), Burgundy (France) (Puisségur, 1976; Rousseau et al., 1994) and Queyras (France) (Magnin, 1991; Rousseau et al., 1994). In each region, samples have been collected away from areas of noticeable human modern impact on the environment (Cameron, 1978; Kerney et al., 1983; Limondin, 1990; Rousseau, 1993). 


\section{Fossil data}

Forty-four fossil assemblages were obtained from the Achenheim loess sequence, located five kilometers west of Strasbourg (Alsace, France) (Fig. 2). This sequence contains a record of important climatic and environment changes for the last 500,000 years. Furthermore, the last climatic cycle, and the related mollusk assemblages selected for this study, showed the strongest temperature variations (Rousseau and Puisségur, 1990). These assemblages, previously analyzed with the analogues method (Rousseau, 1991), are an appropriate set to allow comparisons between both methods, and to test the reliability of the MCR method applied to terrestrial mollusks.

\section{METHODS}

\section{Data homogenization and digitalization.}

The MCR method requires an adjustment of the original data. The meteorological stations yielding temperature values have a heterogeneous distribution over Europe. Consequently, after having defined a mesh of $0.5^{\circ}$ in longitude and latitude, we used an artificial neural network (ANN) (Caudill and Butler, 1992) to estimate mean monthly temperatures at these knots (Fig. 1). We chose the ANN method, instead of any other weighted averaged interpolation, because the thermal altitudinal gradient used by the latter was the same for all the mountains. This led to temperature underestimations, reaching $20^{\circ} \mathrm{C}$ in northern Scandinavia, although in the other regions their estimation is slightly more precise than those obtained from the ANN. This is the reason why we preferred to use an artificial neural network rather than a weighted averaged interpolation.

The artificial neural network used in this study is composed of three layers of processors named neurodes. The input layer contains three neurodes (I-neurodes) for longitude, latitude and elevation of the meteorological stations respectively. The output layer contains twelve neurodes (O-neurodes) corresponding to the monthly climatic parameters of 
the meteorological stations. The middle layer, linking the two others, is composed of several neurodes (M-neurodes), whose number is adjusted after repeated attempts. Each M-neurode receives three sources of information, one per I-neurode, combining them and sending the result to each O-neurode. These latter combine the information they received from the Mneurodes, and allow the comparison of the final result with the observed climatic data. This method has already been described in detail by Peyron (Peyron, 1998). The estimated parameters are then homogeneously distributed in the studied zone.

The interpolated temperatures permitted the definition of isotherms which have been compared with those published by Wallen (Wallen, 1970). Results are similar and local differences are lower or equal to $2^{\circ} \mathrm{C}$. Furthermore the meteorological stations used in our database are more numerous than those used in Wallen's (1970) World Survey of Climatology. Thus, we assume that the results of our interpolations are reliable, and the very small differences observed are negligible.

The geographic distribution of each species has been digitized using the same grid as used for the meteorological stations, in order to more easily link the observations to the climate data (Fig. 3). Presence and absence of species are respectively coded by one and zero at each knot.

\section{Reconstructed parameters}

After determining the temperature and distribution datasets, the next step of our study was to define the most appropriate temperature parameters for the reconstructions. Each digitized species distribution has been compared to twelve digitized monthly temperature maps in order to determine the most significant ecological parameter on this mollusk distribution. In each case we computed the Akaike's (1973) criterion (AIC). This criterion is an extension of the maximum likelihood principle. Its principle is that a decrease of the 
deviance induced by the addition of parameters is compensated by an increase of this deviance proportional to the number of parameters added

$$
\mathrm{AIC}=-2 \Sigma_{\mathrm{i}=1 \text { to } \mathrm{N}} \ln \left(\mathrm{x}_{\mathrm{i}} \mid \theta\right)+2 \mathrm{k}
$$

where $\mathrm{k}$ equals the degrees of freedom of the probabilistic model, and $\mathrm{N}$ equals the number of sites used for the calculation (Akaike, 1973). Thus, this allows the rejection of parameters which do not induce a significant decrease of deviance. For different non-nested probabilistic models based on the same dataset, the smallest AIC indicates the value that best fits the dataset.

A precise generalized linear model will connect the species distribution (y) with a climatic parameter (x). As each species has a thermal optimum for life, we choose by default the quadratic polynomial to link the probability (p) of the expected species distribution (y) with a determined climatic parameter $(\mathrm{x})$. The $(\mathrm{y})$ response being binomial (absence $=0$ and presence=1), a logit link [logit $\mathrm{p}=\ln (\mathrm{p} /(1-\mathrm{p}))]$ was used to avoid any important flattening of the function of probability, and therefore no constants are too small in its equation. Subsequently, the computation of AIC allows the evaluation of the correlation between a single monthly parameter and a species distribution.

Our computation, including geographic distribution and mean monthly temperatures, indicates that cold months are generally related to low AIC, and warm months to high AIC. Such results demonstrate that cold temperatures are a more important limiting factor on the species distributions than warm ones. Furthermore, considering this criterion, there are not enough species in the malacological assemblages to allow a reliable reconstruction for each mean monthly temperature. Thus, as extreme mean monthly temperatures (February and August) cannot always be reconstructed, we preferred three parameters that refer to all the identified species: Tmin, Tmax and Trange. Tmin distribution includes the coldest mean monthly temperatures recorded at each knot of the grid, Tmax the warmest, and Trange the 
annual thermal range, identical to the difference between Tmin and Tmax. The Tmin dataset is composed of values from January and February, and the Tmax dataset of values from July and August. The following calculation of the AIC was carried out on each probabilistic model, linking a geographic species distribution with one of the three parameters Tmin, Trange and Tmax, to validate which ones should be reconstructed.

Our calculations indicate that the limiting factors on the geographic distribution of the terrestrial mollusk species are, in ascending order of their AIC, Tmin, Trange and Tmax for the majority of species. Moreover, for each species, comparison between the lowest AIC of mean monthly temperatures and Tmin does not generally show a strong difference. This supports our reconstruction of Tmin and Trange, which have the lowest AIC in the present study, and the deduction of Tmax through their difference.

\section{Mutual Climatic Range method}

The correspondence between digitized distributions of the species and climate allows the definition of the Specific Climatic Ranges (SCR) in a biplot diagram with Tmin and Trange respectively on the $\mathrm{Y}$ and $\mathrm{X}$ axes (Atkinson et al., 1986) (Fig. 4). The superimposition of the different SCRs for a determined assemblage defines the Mutual Climatic Range (MCR) which is the climatic space shared by all the species in the assemblage. As this MCR is sometimes restrained, its distribution, on each axis, is not necessarily normal or showing welldefined peaks. Thus, the median value of the MCR distribution has been preferred to the mean and the mode, and yielded the most probable estimate on each axis for a modern assemblage. Moreover, for the fossil assemblages, the most probable estimation requests an additional correction applied on the median value. For each reconstructed parameter, this correction is based on the equation of a linear regression between interpolated (from artificial neuronal network) and estimated (from MCR) values from a set of present assemblages from the 
studied area. Error margins of the parameter are the extreme values of the corresponding MCR (Atkinson et al., 1986).

\section{RESULTS}

\section{Modern samples}

The method was first tested on modern assemblages. The interpolated values, at the geographical coordinates of these assemblages, are obtained from the modern dataset using the artificial neural network defined previously. The reconstructed values have been obtained from the mollusk assemblages using the Mutual Climatic Range method. For the 65 assemblages of the six sampled regions, the interpolated Tmins and Tmaxs are included in the error margins of the reconstructed values.

In each of the six regions, the mean of the reconstructed values from the samples yielded the regional Tmin and Tmax. The lowest and highest values of the error margins, for a determined area, represent the regional error margins (Table 1 and Fig. 5). The values of the regional Tmin reconstructions of the three Scandinavian regions (Table 1) are not statistically different. In contrast, those of the three French areas are significantly different from each other and from those in Scandinavia. The values of the regional Tmax reconstruction of both the warmest French regions, Burgundy and Périgord, are significantly different from all the others. In both considered clusters, regional Tmax is significantly equivalent.

These first results show that error margins are generally wider for Tmax reconstructions $\left( \pm 13^{\circ} \mathrm{C}\right)$ than for Tmin ones $\left( \pm 7^{\circ} \mathrm{C}\right)$. The proportionality of the range of the error margin with the value of the reconstructed Tmin and Tmax is an artifact. This is possibly due to the proportionality between the range of the error margin and the specific diversity of the assemblages. Indeed, the specific richness of an assemblage is positively correlated to the regional temperature (Kerney et al., 1983). Consequently the MCR will be narrower. 
The plot of the regional Tmin and Tmax values shows that the European thermal gradient is reconstructed, but that low values are overestimated whereas high values are underestimated. As a consequence, a linear regression has been calculated from the regional values for each parameter (Fig. 5). The equations used to correct the estimated values with regard to the observed ones are:

$$
\begin{aligned}
& \text {-for Tmin: }[\text { Tcalibrated }]=0.63 *[\text { Tpredicted }]-0.91 \text { with } \mathrm{r}^{2}=0.99 \\
& \text {-for Tmax: }\left[\text { Tcalibrated] }=0.44 *[\text { Tpredicted }]+9.00 \text { with } \mathrm{r}^{2}=0.83\right.
\end{aligned}
$$

The standard error of corrected values is lower than $1^{\circ} \mathrm{C}$, thus ranging within the error margins. As the calibration also illustrates that a bias exists between modern estimated and measured temperature values, this correction is likewise used on fossil estimates, in order to provide the best possible temperature reconstructions. As the values of the error margins depend mainly on the climate at the known limits of the geographic distributions of species, they are not subject to the same biases. Thus, these correction equations have not been applied to error margin values. The major problem identified with these error margins appears when, for all the species of an assemblage, there is only a single value in common as MCR. Indeed, extreme values are then identical to the estimated values without correction. Thus the correction shifts the value outside the defined interval of the error margins. A solution is to use the extreme values of a broader MCR containing N-1 species for an $\mathrm{N}$ species assemblage (Fauquette et al., 1998), and calculate a new most probable value on this MCR to keep coherency in the data.

\section{Fossil estimates}

The forty-four assemblages analyzed from the loess sequence at Achenheim have yielded reconstructions of Tmin and Tmax (Table 2). The maximal range for both parameters is around $5^{\circ} \mathrm{C}$, between -4.9 and $-0.1^{\circ} \mathrm{C}$, for Tmin, and between 10.5 and $15.5^{\circ} \mathrm{C}$ for Tmax. The error margins of both parameters are significantly different. For Tmin reconstruction, 
they extend from \pm 4 to $\pm 10^{\circ} \mathrm{C}$, and for Tmax, from \pm 7 to $\pm 18^{\circ} \mathrm{C}$. Contrary to the modern assemblages analyzed previously, the range of the error margins is inversely proportional to the values of the reconstructed Tmin and Tmax. Then, if we assume that the relationship between the range of error margins and reconstructed parameters is an artifact due to the taxonomic diversity of the assemblages, this implies that at Achenheim climatic parameters other than temperature were controlling the specific diversity. These may include moisture and/or precipitation.

The plot of the temperature estimates against depth yielded two curves whose general trends correspond to what may be expected for the last climatic cycle (Fig. 6). Barren samples during the Eemian and at the base of the Late Pleistocene prevented any temperature reconstructions. The Tmin and Tmax curves show similar trends but differences in detail.

Close to the base of the sequence, between 17 and $15 \mathrm{~m}$ depth, both curves show a slight decreasing trend from -1 to $-2.5^{\circ} \mathrm{C}$ and from 14.5 to $13.5^{\circ} \mathrm{C}$, punctuated by a cooling lower than $1^{\circ} \mathrm{C}$ for Tmax. Above the second barren zone, the estimates illustrate a strong twostep warming of around $2.5^{\circ} \mathrm{C}$ between 13 and $12 \mathrm{~m}$ depth. The temperature increases from 3 to $-1^{\circ} \mathrm{C}$, and from 12.5 to $15^{\circ} \mathrm{C}$. Subsequently, both curves indicate decreasing steps in temperature, between 12 and $6 \mathrm{~m}$, from -1 to $-2.5^{\circ} \mathrm{C}$, and 14.5 to $13^{\circ} \mathrm{C}$ respectively. The two steps of the Tmin curve are separated by a strong cooling reaching $-4^{\circ} \mathrm{C}$. This is followed by a strong and abrupt thermal oscillation between 6 and $1 \mathrm{~m}$ in both curves. The oscillations range between -5 and $0^{\circ} \mathrm{C}$ for Tmin, and 10.5 and $15.5^{\circ} \mathrm{C}$ for Tmax. The depth and magnitude of peaks in both curves correspond except at $3 \mathrm{~m}$ where the magnitude of Tmax is two fold that of Tmin. Furthermore, two important coolings occur around $6 \mathrm{~m}$ and $2 \mathrm{~m}$ depth. In the last meter, both curves show a rising trend from -5 to $-1^{\circ} \mathrm{C}$, and from 11 to $14.5^{\circ} \mathrm{C}$, followed by a fall to $13^{\circ} \mathrm{C}$ for Tmax. 


\section{DISCUSSION}

Intrinsic problems of the MCR method

The method is based on a correspondence between species distribution and temperature. Each temperature reconstruction performed on present day assemblages should have led to values equal to those measured from meteorological stations. Our study shows, as Atkinson et al. (1987) indicated with beetles, that a bias exists between interpolated and reconstructed values. A calibration on present day data has been used to determine a correction to be applied to present day and fossil temperature estimates. Does this mean that a correction, based on a local calibration, could be applied everywhere, or is a worldwide calibration required?

A species distribution is frequently dependent on several environmental parameters. Indeed, if a species occurrence is constrained by a determined range of tolerance to a climate parameter, this range can shift under the influence of other parameters. If the calibration between the species presence and a climate parameter, established in a particular region is used to correct values of this parameter in another region, the correction will not be valid (Elias, 1997; Elias et al., 1999). Only if the calibration could be carried out on a worldwide area, or at least on the complete distribution, would the problem of shifting regional tolerance be solved. On the contrary, this worldwide calibration would smooth all the different regional climatic characteristics related to their geographical location (i.e., plain, mountain, or coast...). Taking into account this problem, (Elias et al., 1999) use regional calibrations, based on modern samples from areas whose geographical characteristics are similar to those of the considered fossil sites. Then the present reconstructed values from beetle assemblages best fit the observed parameters. However, such method implies the precise knowledge of the location of the fossil assemblages, and thus the determination of the boundaries of the present regional calibration area. Consequently, as the test of the MCR method on mollusk data has 
been realized to avoid the use of the analogues assemblages, this regional calibration has not been used in your study. This easier correction is then used by default, and does not take into account what could be the origin of this bias. Indeed, it is observed in thermal reconstructions based on insects (Atkinson et al., 1987) and mollusks (present study). For pollen (Fauquette et al., 1998), this bias is not similarly noticed, although this method was applied to Tertiary pollen; they used a pretreatment, gathering pollen species in ecological groups in the calculation of the most probable interval. So, their MCR method is not similar to our technique. Consequently, their correlation coefficients cannot be compared with the bias we recognize in this study. Finally, the test of the Hokr method, applied to rodents (Chaline and Brochet, 1989), using only one present day fauna, does not provide a comparable dataset to resolve this problem.

A first hypothesis is that this bias could be due to the incomplete species distributions used in the definition of the Specific Climatic Range (SCR), by being based only on the European malacological atlas of Kerney et al. (1983). Indeed, if the complete specific distributions are not available as plotted in Kerney's atlas (mainly in areas of extreme temperatures), the real extreme thermal limits of the SCR will not be reached. Thus the reconstructions of Tmin and Tmax produced from the calculation of the most probable value will be respectively overestimated and underestimated. This hypothesis could explain the observed bias, but as it has been detected also in insects, for which the complete specific distributions were used, another explanation must be sought. Moreover, a lack of meteorological stations may not necessary originate the bias, because this would imply that colder temperatures have not been recorded. Thus, as colder mean monthly temperatures mostly occur beyond the Petchora River (Russia), their occurrence in Finland is strongly improbable. Thus, the low number of meteorological stations in Finland is not assumed to impose any bias. Finally, as the characteristics of the considered bias differ from those (Tmin 
and Tmax overestimated) proposed if northward species migration was at its origin, the latter hypothesis is rejected. Our assumption also considers restrained geographical distributions under any drastic environmental conditions before the geographical mapping of the species.

A second hypothesis is that the mode of calculation of the most probable value of the MCR, used for insects and mollusks, is not reliable. In both cases, the SCR are unweighted, and the number of individuals of the species not taken into account. This calculation, as we used it, assumes that all the climatic couplets included in the MCR, and thus in each SCR, have the same weighting; that is probably wrong. Moreover, the use of the number of individuals of each species could be used carefully. On the one hand, the relative abundance of the species can be due to taphonomic processes acting between the biocenose and the taphocenose. However, the shells, grouped in particular structures by water, are relatively well detected during the sampling. On the other hand, the relative abundance of the species can be due to one or more climatic parameters, different from those reconstructed. . The comparison of the modern distribution of the species and those of climatic parameters might help solving this problem. Thus, improving the step-like variations would be more difficult. Consequently, the use of weighted SCRs, from the climatic dataset or from the relative abundance of species, in the calculations of the most probable thermal values of the MCR would probably allow the reconstruction of more extreme, and realistic, temperatures during cold periods.

A third hypothesis takes into account that mollusks can be in dormancy during winter and summer, buried in the soil or under rocks, or settled on plants. Indeed, although the whole geographic distributions of beetle species are used in the Mutual Climatic Range method since its first application (Atkinson et al., 1986), the bias subsists. (Elias, 1997) hypothesized that this could be due to the dormancy period of species. So, the significance of the extreme temperatures of some Specific Climatic Ranges appears not to be always directly related to 
mollusks physiology. Unless the whole geographic distribution of terrestrial mollusks species is known, we can not presently specify how important the dormancy on climatic reconstructions is.

A fourth hypothesis is that the presence of certain species in a sample could be due to favorable local environmental characteristics other than regional climate. If the allochthonous species are directly linked to ecological climatic characteristics different from those of the sample region, this will lead to biased reconstructions.

The maps of the malacological atlas of Kerney et al. (1983), have been interpolated through the location of both field and collection samples. The presence of species may have been assigned to certain regions, where they were never sampled, and vice versa. This can then modify the SCR, the MCR and hence the values reconstructed, especially if the regions, missing or incorrectly assigned, present important magnitudes of parameter values. To avoid these problems, a joint effort should be made between the mapping of present day malacological distributions and those collecting fossil mollusk samples and their related temperatures.

\section{Comparison between analogues and Mutual Climatic Range methods}

The general trends of the curves of the two methods are similar for the last climatic cycle, but differences remain (Fig. 6). Between 17 and 15 m depth, the analogues curves show strong variations that are not described through using MCR. Between 13 and $8 \mathrm{~m}$ depth, variations in the analogues curves show an increase followed by a decrease, whereas the MCR curves show the same variations but separated by a step. This scheme is repeated between 8 and $6 \mathrm{~m}$ depth, except that there is no increase at the beginning of this cycle for the MCR Tmax curve. During the coldest stage, between $6 \mathrm{~m}$ and $1 \mathrm{~m}$ depth, the thermal minima and maxima of both Tmin curves are located at the same depth (except at $4 \mathrm{~m}$ ); the correspondent values for the MCR curve are higher than for the analogue method, mainly at the minima. 
During the same cold stage, the Tmax curves are in phase, except between 2.5 and $1 \mathrm{~m}$, with minimal values of the MCR curves generally lower than those of the analogues. Between $1 \mathrm{~m}$ and $0 \mathrm{~m}$, where the analogues curves show a constant increase of temperature, the MCR curves describe an increase followed by a decrease in temperature.

The analogues minimal temperature curve has a greater variability than its corresponding MCR, mainly in the coldest stage. This lack of variability could come from the “incomplete” Specific Climatic Ranges only defined from western and central Europe distributions; these do not include climatic conditions similar to the Last Glacial Maximum. Lack of variability could also be partially induced by the non-use of the number of individuals of a species. Thus reconstructed minimum temperatures from the Mutual Climatic Range are milder than what could be expected. For the maximum temperature, opposite variability comes from the dataset itself. Indeed there is a linear correlation between Tmin and Trange $\left(r^{2}=0.8\right)$. Consequently, weak Tmin is associated with high Trange. As variations of Tmin in several assemblages are smaller than associated variations of Trange, this implies strong variability in the Tmax curve reconstructed with the MCR method. Differences of variability between the two methods could also come from the estimation of the most probable value, as previously mentioned. The steps present on the curves of the Mutual Climatic Range reconstruction are due to equivalent assemblage composition, whose number of individuals in a species could not be used to differentiate them. Some small differences of variation remain unexplained, like those between 17 and $15 \mathrm{~m}$ depth. For the analogues curves, they might be related to the number of species whose variations are equivalent. The calculation of the correlation coefficient between reconstructed Tmin and Tmax, and the number of individuals of Pupilla muscorum, Succinea oblonga and Trichia hispida (numerous individuals in assemblages) did not reveal a strong influence of these well-represented species on the 
reconstruction of the climatic parameters with the MCR. Thus, these differences between the two methods of reconstruction remains unexplained.

\section{CONCLUSION}

Among the different thermal factors tested here, the mean temperature of the coldest month and the annual thermal range are the most constraining parameters on the geographical distribution of terrestrial mollusks species. However, the impact of other parameters on species distributions, such as humidity or evapotranspiration, remains to be tested. This requires more appropriate meteorological databases than those presently used. The interaction of different climatic and biological parameters must not be neglected.

The first application of the MCR method on modern terrestrial mollusk assemblages yields thermal values close to the measured ones. We find that the MCR method applied on gastropods is therefore an appropriate and reliable tool to reconstruct seasonal temperature; other climatic parameters shall be incorporated in the future. A bias has been noticed, between modern estimated and measured temperatures, and is similar to the differences determined when applying the same method to beetle assemblages. Complementary studies are necessary to confirm the methodological or biological origin of this bias.

The results produced from the application of the MCR method to fossil mollusk assemblages confirm its usefulness in yielding a proxy temperature record for the Late Pleistocene. Nevertheless, problems of reduced variability in the climate signal and reaching the coldest temperatures have been clearly recognized. Improvement of the transfer function, by using the number of individuals or the weighted Specific Climatic Ranges, should help us to reduce methodological and ecological problems.

The results, obtained on recent and fossil European mollusk assemblages, indicate that the MCR method can be safely applied to terrestrial gastropods to reconstruct variations of past climatic parameters. Continued development of the MCR method for terrestrial mollusks 
assemblages will make it a vital tool in the climate reconstruction of Quaternary sequences worldwide.

\section{ACKNOWLEDGEMENTS}

We thank J. Guiot and C. Goeury (IMEP of Aix-Marseille III, France) for providing us the PPPhalos software (http://medias.obs-mip.fr/paleo_utils/), E. Paradis for his help in using the software R -A Language and Environment software (Ihaka and Gentleman, 1996) (http://cran.r-project.org), and A. Chepstow-Lusty for editorial help. This is Institut des Sciences de l'Evolution de Montpellier contribution ISEM 2001-063, and Lamont-Doherty Earth Observatory of Columbia University contribution 6235.

\section{REFERENCES}

Akaike, H. (1973). Information Theory and an Extension of the Maximum Likelihood Principle. In "Second International Symposium on Information Theory.” (B. N. Petrov, and K. Csaki, Eds.), pp. 267. Akademiai Kiado, Budapest.

Andersen, J., and Halvorsen, O. (1984). Species Composition, Abundance, Habitat Requirements and Regional Distribution of Terrestrial Gastropods in Arctic Norway. Polar Biology 3, 45-53.

Armitage, K., and Stinson, D. (1980). Metabolic acclimation to temperature in a terrestrial snail. Comparative Biochemistry and Physiology 67A, 135-139.

Atkinson, T. C., Briffa, K. R., and Coope, G. R. (1987). Seasonal temperatures in Britain during the past 22,000 years, reconstructed using beetle remains. Nature 325, 587-592. Atkinson, T. C., Briffa, K. R., Coope, G. R., Joachim, M. J., and Perry, D. W. (1986). Climatic calibration of coleopteran data. In "Handbook of Holocene Palaeoecology and Palaeohydrology.” (B. E. Berglund, Ed.), pp. 851-859. Wiley, J. \& Sons Ltd., Chichester. 
Biannic, M., Coillot, J.-P., and Daguzan, J. (1995). Circadian cardiac rhythm in relation to environmental variables in the snail Helix aspersa Müller. Journal of Molluscan Studies 61, 289-292.

Blazka, P. (1953). Der tägliche Rhythmus des Gesamtmetabolismus in der Weinbergschnecke (Helix pomatia L.). Acta Societatis Zoologicae Bohemoslovenicae 17, 251-265.

Bouillon, J. (1956). Influence of temperature on the Histological Evolution of the Ovotestis of Cepea nemoralis L. Nature 177, 142-143.

Cameron, R. A. D. (1978). Historical and ecological determinants of some land mollusc faunas in Britain. In “Atti IV Congresso della Societa Malacologia Italiana Siena.”, pp. 193-194.

Caudill, M., and Butler, C. (1992). “Understanding Neural Networks: Basic Networks. Vol. 1.” The MIT Press.

Chaline, J., and Brochet, G. (1989). Les rongeurs - Leurs significations paléoécologiques et paléoclimatiques. In “La Baume de Gigny (Jura).” (M. Campy, J. Chaline, and M. Vuillemey, Eds.), pp. 97-109. Editions du Centre National de la Recherche Scientifique, Paris.

Chevallier, H. (1982). Facteurs de croissance chez des gastéropodes pulmonés terrestres paléarctiques en élevage. Haliotis 12, 29-46.

Dainton, B. (1954). The activity of slugs. I: The induction of activity by changing temperature. Journal of Experimental Biology 31, 165-187.

Elias, S. A. (1997). The Mutual Climatic Range method of paleoclimate reconstruction based on insect fossils: new applications and interhemispheric comparisons. Quaternary Science Reviews 16, 1217-1225.

Elias, S. A. (2000). Late Pleistocene Climates of Beringia, Based on Analysis of Fossil Beetles. Quaternary Research 53, 229-235. 
Elias, S. A., Andrews, J. T., and Anderson, K. H. (1999). Insights on the climatic constraints on the feetle fauna of coastal Alaska, USA, derived from the Mutual Climatic Range method of paleoclimate reconstruction. Arctic, Antarctic and Alpine Research 31, 9498.

Fauquette, S., Guiot, J., and Suc, J.-P. (1998). A method for climatic reconstruction of the Mediterranean Pliocene using pollen data. Palaeogeography, Palaeoclimatology, Palaeoecology 144, 183-201.

Franc, A. (1968b). Sous-classe des Pulmonés. In “Traité de zoologie - Mollusques gastéropodes et scaphopodes.” (P.-P. Grassé, Ed.), pp. 325-607. Masson et Cie, Paris (VIe).

Fritts, H. C., Blasing, T. J., Hayden, B. P., and Kutzbach, J. E. (1971). Multivariate techniques for specifying tree-growth and climate relationships and for reconstructing anomalies in paleoclimate. Journal of applied meteorology 10, 845-864.

Gasse, F., and Tekaia, F. (1983). Transfer functions for estimating paleoecological conditions (pH) from East African diatoms. Hydrobiologia 103, 85-90.

Gomot, L., and Griffond, B. (1993). Action of epigenetic factors on the expression of hermaphroditism in the snail Helix aspersa. Comparative Biochemistry and Physiology 104A, 195-199.

Gomot, P., Griffond, B., and Gomot, L. (1986). Effets de la température sur la spermatogénèse d'Escargots Helix aspersa maintenus en repos artificiel. Comptes rendus de l'Académie des Sciences de Paris 302, 27-32.

Guiot, J. (1986). ARMA techniques for modelling tree-ring response to climate and for reconstructing variations of paleoclimates. Ecological Modelling 33, 149-171.

Guiot, J. (1987). Late Quaternary Climatic Change in France Estimated from Multivariate Pollen Time Series. Quaternary Research 28, 100-118. 
Guiot, J. (1994). Statistical analyses of biospherical variability. In "NATO ASI Series, Vol. I22: Long-Term Climatic Variations.” (J.-C. Duplessy, and M.-T. Spyridakis, Eds.). Springer Verlag, Heidelberg.

Huntley, B., and Prentice, C. (1988). July temperatures in Europe from pollen data. Science 241, 687-690.

Ihaka, R., and Gentleman, R. (1996). R: A Language for Data Analysis and Graphics. Journal of Computational and Graphical Statistics 5, 299-314.

Imbrie, J., and Kipp, N. G. (1971). A new micropaleontological method for quantitative paleoclimatology: application to a late Pleistocene Carribean core. In "The late Cenozoic glacial ages.” (K. K. Turekian, Ed.), pp. 71-181. Yale Univ. Press, New Haven.

Imbrie, J., Hays, J. D., Martinson, D. G., McIntyre, A., Mix, A. C., Morley, J. J., Pisias, N. G., Prell, W. L., and Shackleton, N. J. (1984). The orbital theory of Pleistocene climate : support from a revised chronology of the marine $\delta^{18} \mathrm{O}$ record. In "Milankovitch and Climate.” (A. Berger, J. Imbrie, J. Hays, G. Kukla, and B. Saltzman, Eds.), pp. 269305. Reidel Publ. Comp., Dordrecht.

Kerney, M. P., Cameron, R. A. D., and Jungbluth, J. H. (1983). “Die Landschnecken Nordund Mitteleuropas.”, Hamburg und Berlin.

Langley, C. K. (1979). Thermal acclimation of a central neurone of Helix aspersa. I. Effects of temperature on electrolyte levels in the haemolymph. Journal of Experimental Biology 78, 181-186.

Leemans, R., and Cramer, W. (1991). “The IIASA Climate Database for mean monthly values of temperature, precipitation and cloudiness on a global terrestrial grid.”, International Institute of Applied Systems Analysis. 
Light, J. M., and Killeen, I. (1996). Cartographie de la répartition des mollusques continentaux dans les îles britanniques. Vertigo 6, 33-40.

Limondin, N. (1990). "Paysages et climats quaternaires par les mollusques continentaux." Unpublished Doctorat d'Université thesis, Univ. Paris I Panthéon-Sorbonne.

Lozek, V. (1964). Quartärmollusken der Tschechoslowakei. Rozpravy Ustredniho ustuvu geologického 31, 1-374.

Magnin, F. (1991). "Mollusques continentaux et histoire quaternaire des milieux méditerrannéens (Sud-Est de la France, Catalogne).” Unpublished Doctorat d'Université thesis, Univ. Aix-Marseille II.

Montuire, S. (1999). Mammalian faunas as indicators of environmental and climatic changes in Spain during the Pliocene-Quaternary transition. Quaternary Research 52, 129-137.

Mourguiart, P., Corrège, T., Wirrmann, D., Argollo, J., Montenegro, M. E., Pourchet, M., and Carbonel, P. (1998). Holocene paleohydrology of lake Titicaca estimated from an ostracod-based transfer function. Palaeogeography, Palaeoclimatology, Palaeoecology 143, 51-72.

Nilsson, A. (1968). “De pa land levande molluskerna inom Abisko Nationalpark. Redogörelse för undersökningar utförda aren 1966-1967.” Stencil, Landskrona.

Nilsson, A. (1987). Terrestrial mollusks from the western part of the Torneträsk area. Fauna norrlandica 5, 2-16.

Overpeck, J. T., Webb III, T., and Prentice, I. C. (1985). Quantitative interpretation of fossil pollen spectra: dissimilarity coefficients and the method of modern analogs. Quaternary Research 23, 87-108.

Pelseneer, P. (1935). “Essai d'Ethologie zoologique d'après l'étude des Mollusques.” Fondation A. de Potter. 
Peyron, O. (1998). "Le climat de l'Europe et de l'Afrique au dernier maximum glaciaire et à l'Holocène moyen.” Unpublished Doctorat d'Université thesis, Univ. Aix-Marseille III. Phifer, C. B., and Prior, D. J. (1985). Body hydratation and haemolymph osmolality affect feeding and its neural correlate in the terrestrial gastropod, Limax maximus. Journal of Experimental Biology 118, 405-421.

Pokryszko, B. M. (1989). Snail fauna of calcareous fens in the Dovrefjell (Norway). In "Proceedings of the tenth international malacological congress." (C. Meier-Brook, Ed.), pp. 443-446. Unitas Malacologica, Tübingen.

Puisségur, J.-J. (1976). Mollusques continentaux quaternaires de Bourgogne. Significations stratigraphiques et climatiques. Rapports avec d'autres faunes boréales de France. Mémoires géologiques de l'Université de Dijon 3, 1-241.

Rollo, D. C. (1991). Endogenous and exogenous regulation of activity in Deroceras reticulatum, a weather-sensitive terrestrial slug. Malacologia 33, 199-220.

Rousseau, D.-D. (1991). Climatic Transfer Function from Quaternary Molluscs in European Loess Deposits. Quaternary Research 36, 195-209.

Rousseau, D.-D. (1993). Holocene Environmental Signals from Mollusk Assemblages in Burgundy (France). Quaternary Research 40, 237-253.

Rousseau, D.-D., Limondin, N., Magnin, F., and Puisségur, J.-J. (1994). Temperature oscillations over the last 10,000 years in western Europe estimated from terrestrial mollusc assemblages. Boreas 23, 66-73.

Rousseau, D.-D., Preece, R., and Limondin-Lozouet, N. (1998a). British late glacial and Holocene climatic history reconstructed from land snail assemblages. Geology 26, 651-654. 
Rousseau, D.-D., Zöller, L., and Valet, J.-P. (1998b). Late Pleistocene Climatic Variations at Achenheim, France, Based on a Magnetic Susceptibility and TL Chronology of Loess. Quaternary Research 49, 255-263.

Rousseau, D.-D., and Puisségur, J.-J. (1990). A 350,000-years climatic record from the loess sequence of Achenheim, Alsace, France. Boreas 19, 203-216.

Sacchi, C. F., and Testard, F. (1971). “Ecologie Animale - Organismes et Milieu.” Doin, Paris.

Uminski, T. (1975). Life cycles in some Vitrinidae (Mollusca, Gastropoda) from Poland. Annales Zoologici 33, 17-33.

Waelbroeck, C., Labeyrie, L., Duplessy, J.-C., Guiot, J., Labracherie, M., Leclaire, H., and Duprat, J. (1998). Improving past sea surface temperature estimates based on planktonic fossil faunas. Paleoceanography 13, 272-283.

Wallen, C. C. (1970). "World Survey of Climatology. Volume 5. Climates of Northern and Western Europe.” Elsevier Publishing Company, Amsterdam-London-New York.

Watabe, N. (1983). Shell Repair. In "The Mollusca. vol. 4: Physiology.” (W. D. RussellHunter, Ed.), pp. 289-316. Academic Press.

Webb III, T., and Bryson, R. A. (1972). Late- and postglacial climatic change in the northern Midwest, USA: quantitative estimates derived from fossil pollen spectra by multivariate statistical analysis. Quaternary Research 2, 70-115. 

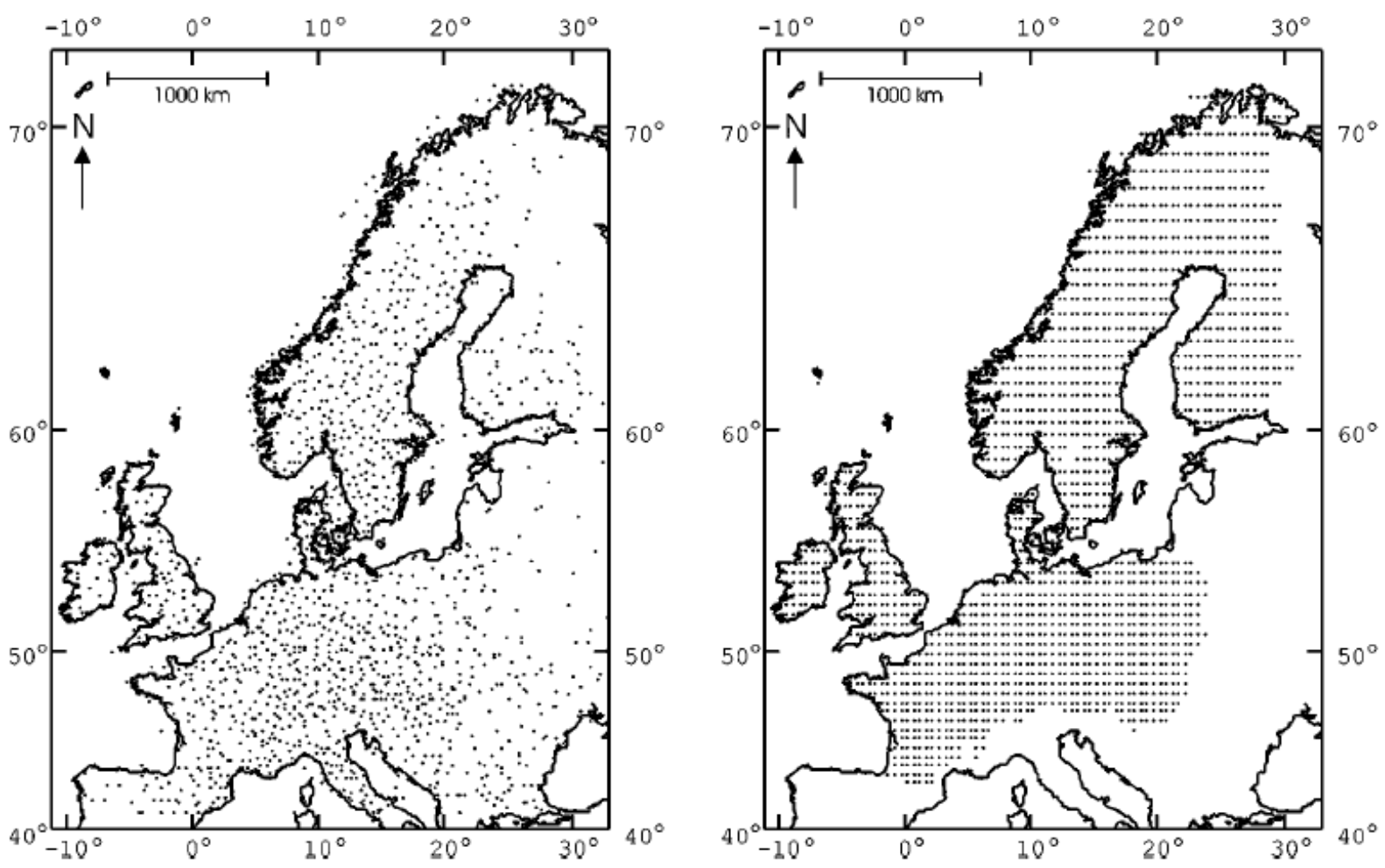

Figure. 1

Map showing the meteorological stations in Europe from the Leemans and Cramer (1991) database (on the left), and from the grid defined in this study (on the right). 


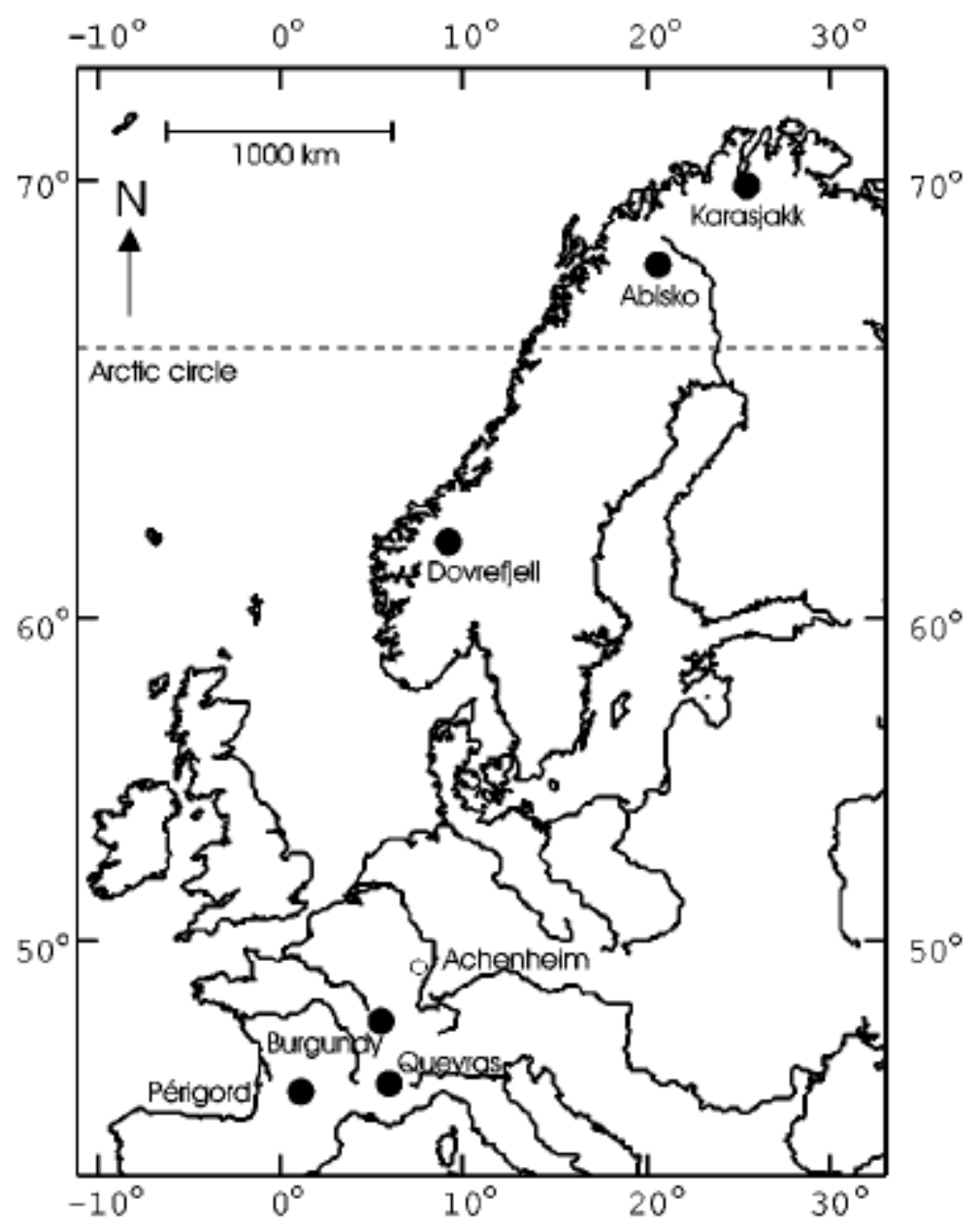

Figure. 2.

Location of the present sampling regions (filled circles) and fossil site (empty circle).

Filled circles include several sampling localities. 


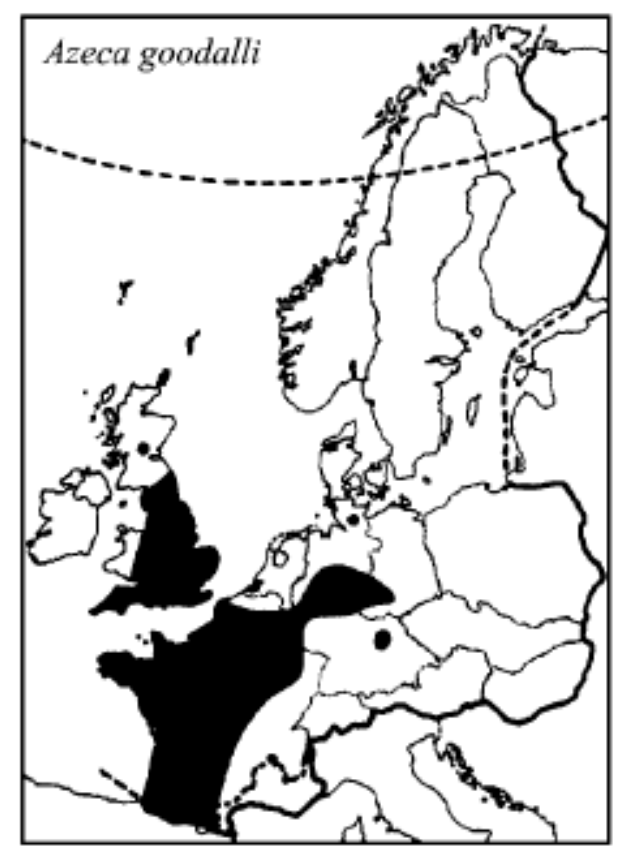

A

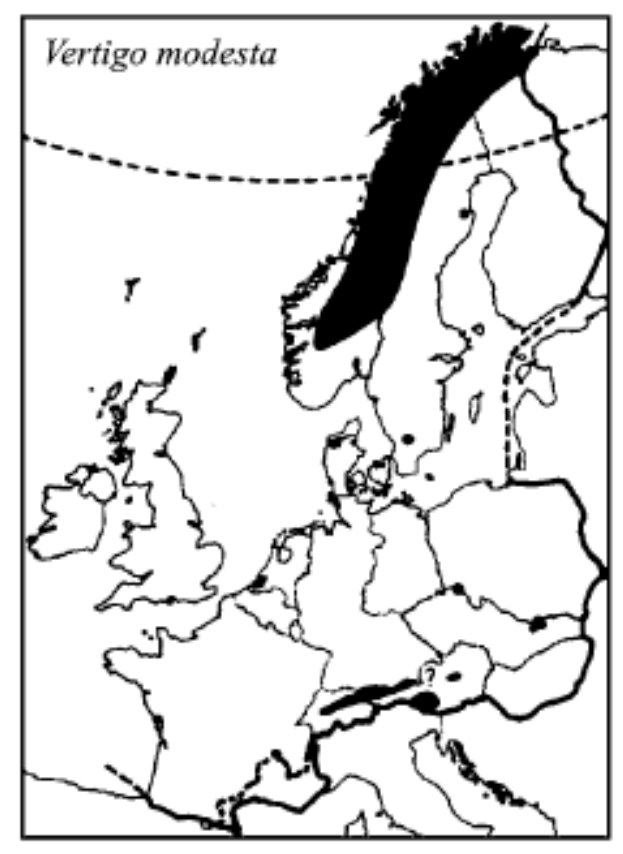

C

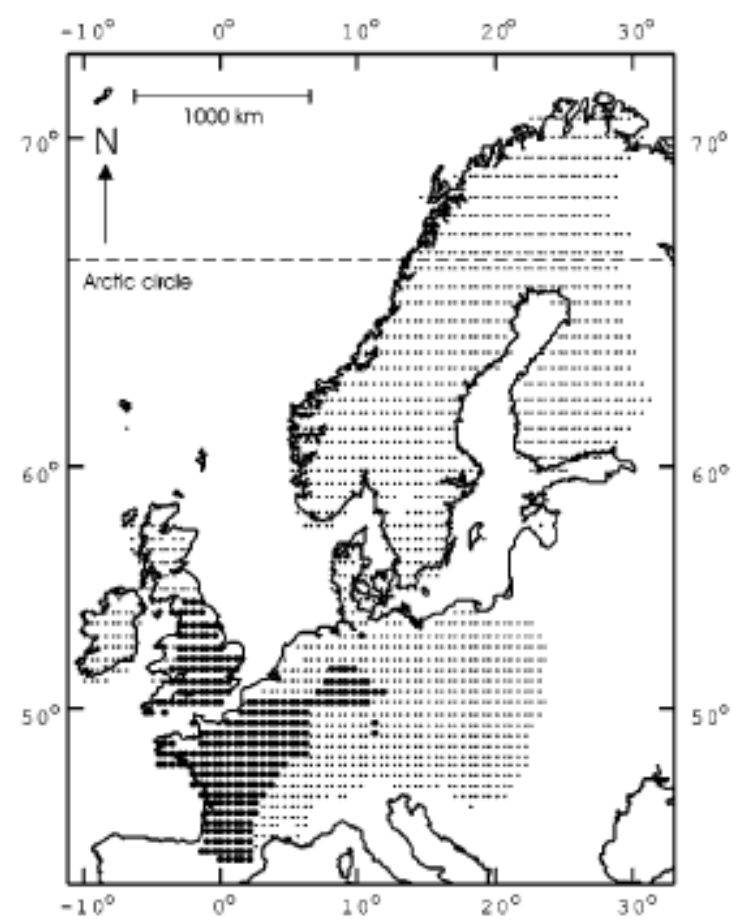

B

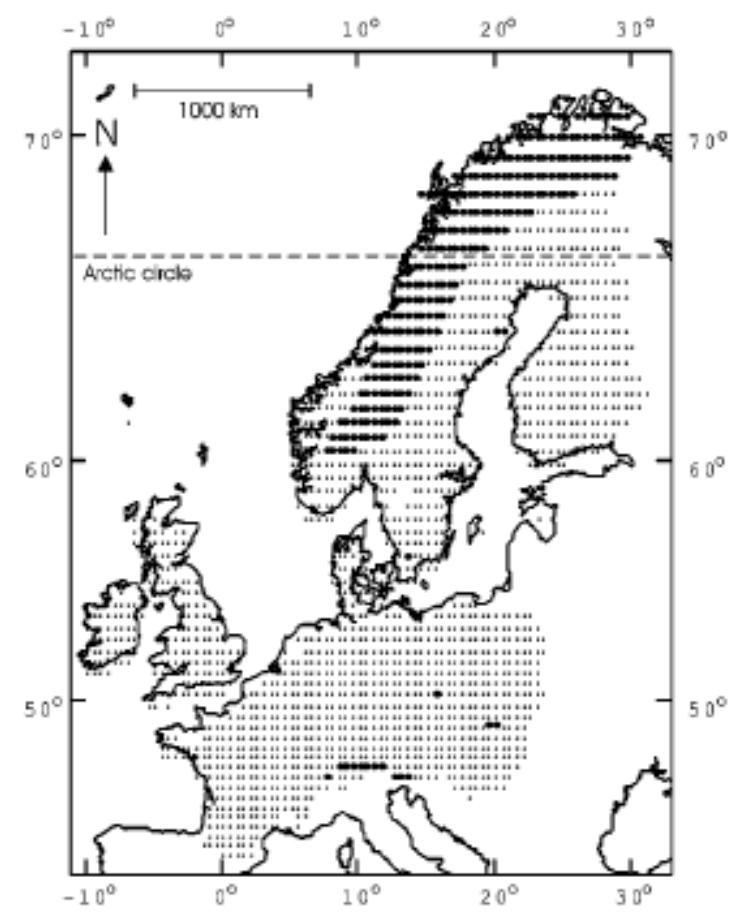

D

Figure. 3. Geographic distributions of the species Azeca goodalli and Vertigo modesta from the malacological atlas of Kerney et al. (1983) (A and C, respectively) and digitalized distributions with the grid defined in this study (B and D, respectively). On A and C, presenceis represented by a black area; on $\mathrm{B}$ and $\mathrm{D}$, it is characterized by large dots. 


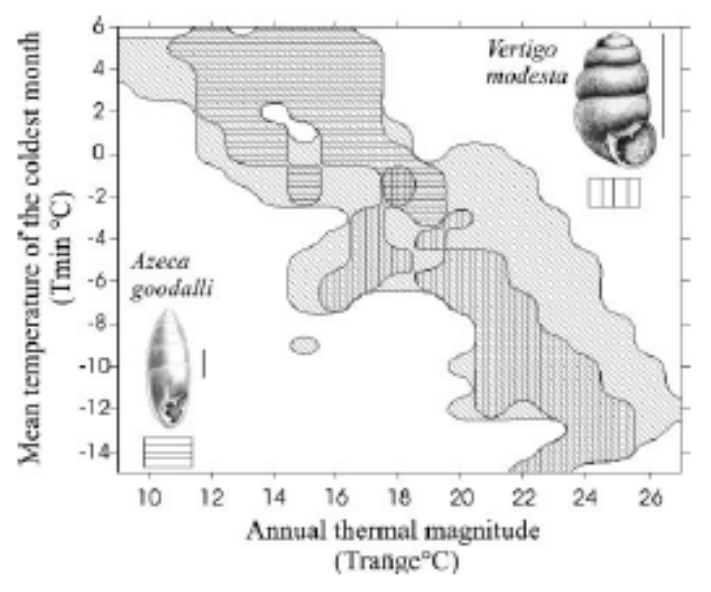

Figure. 4. Specific climatic ranges (SCR) and mutual climatic range (MCR) determined for the species Azeca goodalli (horizontal lines) and Vertigo modesta (vertical lines) and for the studied zone (diagonal lines). The SCRs are the climatic envelopes of the species, and the MCR is the climatic area shared by the envelopes of all the species of the assemblage. The length of the scale near shells is $3 \mathrm{~mm}$.

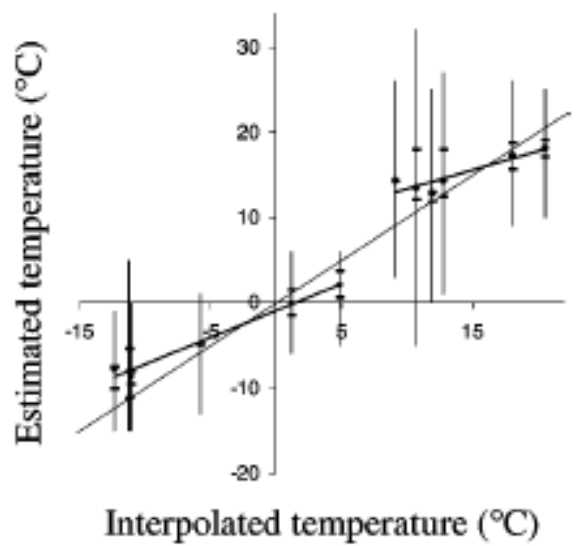

Figure. 5. Comparison between measured and estimated minimal (Tmin) and maximal (Tmax) monthly mean temperature temperatures of the six modern sampled regions. Each region gathers several sampled locations (Table 1). Each regional error margin (vertical lines) comprises the two extreme MCR limits from its local reconstructions. Each regional estimated mean temperature (black dots) is the mean of the values reconstructed from its samples. For each region, the two horizontal ticks limit the dispersion range of its local estimated mean temperatures. 


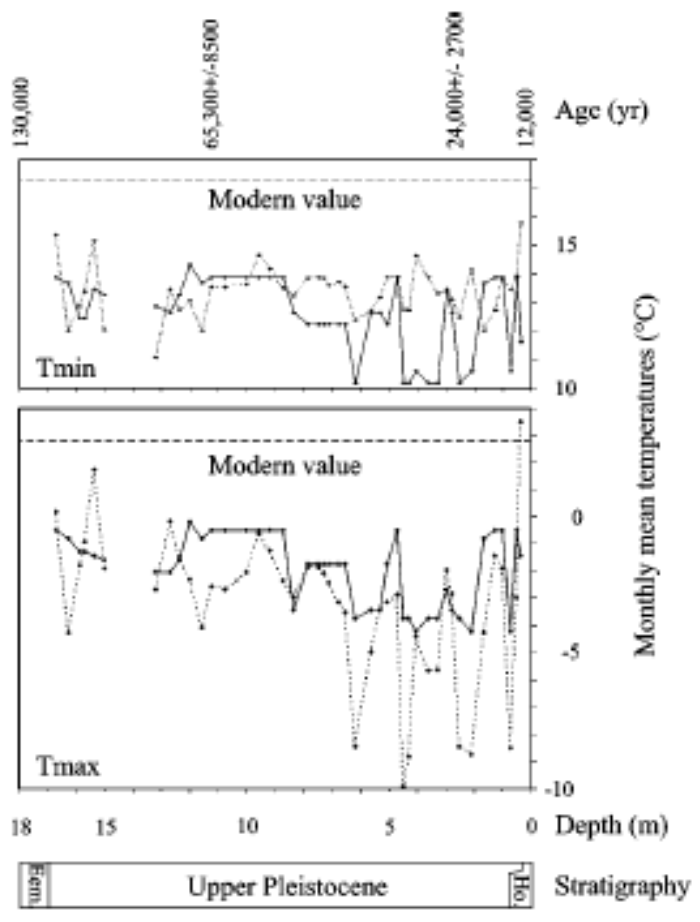

Figure. 6. Variations of Tmin and Tmax reconstructed from the malacological assemblages of Achenheim (Alsace, France) with the analogues method (dotted lines) and with the MCR method (straight lines). Ho. D Holocene; Eem. D Eemian. Temperatures reconstructed from the MCR and the analogue methods are represented by a straight line and a dotted line, respectively. For each assemblage, because error margins of estimates overlap, they were not plotted in order to clarify this scheme. TL dating are from Rousseau et al. (1998b), and the inferior boundaries of the Eemian and the Holocene are from Imbrie et al. (1984). 
TABLE 1

Interpolated and Estimated Temperatures for Modern European Assemblages

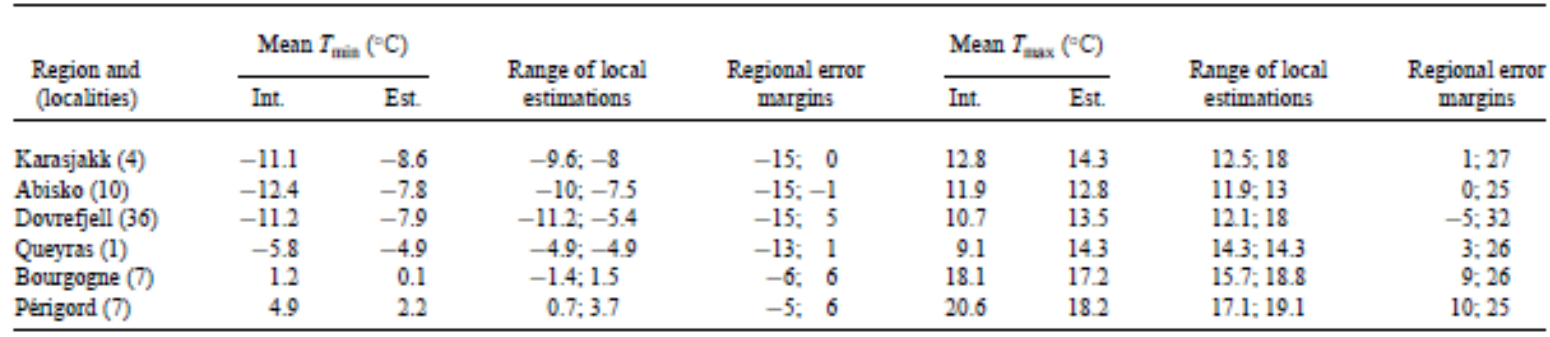

Note. Int. are the modern interpolated values with the artificial neural network; and Est.- the modern estimated values with the mutual climatic range (MCR) method on mollusk assemblages. The estimated values of Tmin have been calculated with the median applied on the MCR distributions along the Tmin axis. The estimated values of Tmax have been deduced from the difference between Trange and Tmin. The minimal value of the error margins is the minimal value for the MCR, and the maximal value is deduced by addition as Tmax. In the range of local estimations, the values are calculated for the entire locality of a region. For each region, the regional error margins are determined by taking the two extreme values of the MCRs boundaries for the entire localities. 
TABLE 2

Estimated Temperatures for Fossil Assemblages from Achenheim (Alsace, France)

\begin{tabular}{|c|c|c|c|c|c|c|}
\hline \multirow[b]{3}{*}{ Sample } & \multirow[b]{3}{*}{ Depth } & \multirow{3}{*}{$\begin{array}{l}\text { Number of } \\
\text { species }\end{array}$} & \multicolumn{2}{|c|}{$T_{\min }$ corrected $\left({ }^{\circ} \mathrm{C}\right)$} & \multirow{2}{*}{\multicolumn{2}{|c|}{$T_{\max }$ corrected $\left({ }^{\circ} \mathrm{C}\right)$}} \\
\hline & & & \multirow{2}{*}{$\begin{array}{l}\text { MCR } \\
\text { range }\end{array}$} & \multirow{2}{*}{$\begin{array}{l}\text { Median } \\
\text { MCR }\end{array}$} & & \\
\hline & & & & & Range & $\overline{T_{\text {min }}+T_{\text {mange }}}$ \\
\hline q26p & 0.348 & 11 & $-9 ; 6$ & -1.9 & 6 to 29 & 14.6 \\
\hline $\mathrm{q} 25 \mathrm{p}$ & 0.522 & 5 & $-9 ; 6$ & -1.6 & 0 to 30 & 15.4 \\
\hline $\mathrm{q} 24 \mathrm{p}$ & 0.739 & 4 & $-7 ; 1$ & -4 & 8 to 23 & 13.8 \\
\hline$q 23 p$ & 1.001 & 5 & $-9 ; 6$ & -1.6 & 0 to 30 & 15.4 \\
\hline $\mathrm{q} 22 \mathrm{p}$ & 1.262 & 4 & $-9 ; 6$ & -1 & 0 to 29 & 15.8 \\
\hline $\mathrm{q} 21 \mathrm{p}$ & 1.653 & 3 & $-12 ; 6$ & -1.1 & -3 to 30 & 15.8 \\
\hline $\mathrm{q} 20 \mathrm{p}$ & 2.088 & 2 & $-7 ; 1$ & -4 & 8 to 23 & 13.8 \\
\hline $\mathrm{q} 19 \mathrm{p}$ & 2.523 & 7 & $-7 ; 1$ & -3.7 & 9 to 23 & 13.6 \\
\hline $507 \mathrm{p}$ & 2.784 & 6 & $-7 ; 1$ & -3.5 & 9 to 23 & 14.8 \\
\hline 508p & 2.958 & 8 & $-7 ; 1$ & -3 & 9 to 23 & 15.2 \\
\hline $\mathrm{q} 17 \mathrm{p}$ & 3.306 & 9 & $-7 ; 1$ & -3.7 & 9 to 23 & 13.6 \\
\hline$q 16 p$ & 3.611 & 8 & $-7 ; 1$ & -3.7 & 9 to 23 & 13.6 \\
\hline q15p & 4.046 & 7 & $-7 ; 1$ & -4 & 8 to 23 & 13.8 \\
\hline q14p & 4.306 & 6 & $-7 ; 1$ & -3.7 & 9 to 23 & 13.6 \\
\hline q13p & 4.481 & 6 & $-7 ; 1$ & -3.7 & 9 to 23 & 13.6 \\
\hline s10p & 4.705 & 4 & $-9 ; 6$ & -1.6 & 0 to 30 & 15.4 \\
\hline sllp & 5.046 & 5 & $-9 ; 5$ & -2.4 & 5 to 28 & 14.7 \\
\hline $\mathrm{s} 12 \mathrm{p}$ & 5.307 & 6 & $-7 ; 1$ & -3.5 & 9 to 23 & 14.8 \\
\hline sl3p & 5.655 & 5 & $-7 ; 1$ & -3.5 & 9 to 23 & 14.8 \\
\hline qlip & 6.177 & 8 & $-7 ; 1$ & -3.7 & 9 to 23 & 13.6 \\
\hline $514 p$ & 6.525 & 4 & $-9 ; 5$ & -2.4 & 5 to 28 & 14.7 \\
\hline s15p & 6.743 & 5 & $-9 ; 5$ & -2.4 & 5 to 28 & 14.7 \\
\hline s16p & 7.134 & 5 & $-9 ; 5$ & -2.4 & 5 to 28 & 14.7 \\
\hline s17p & 7.308 & 6 & $-9 ; 5$ & -2.4 & 5 to 28 & 14.7 \\
\hline s18p & 7.482 & 6 & $-9 ; 5$ & -2.4 & 5 to 28 & 14.7 \\
\hline $\mathrm{s} 19 \mathrm{p}$ & 7.83 & 6 & $-9 ; 5$ & -2.4 & 5 to 28 & 14.7 \\
\hline $520 \mathrm{p}$ & 8.352 & 6 & $-7 ; 1$ & -3.5 & 9 to 23 & 14.8 \\
\hline $521 \mathrm{p}$ & 8.7 & 4 & $-9 ; 6$ & -1.6 & 0 to 30 & 15.4 \\
\hline $522 \mathrm{p}$ & 9.178 & 5 & $-9 ; 6$ & -1.6 & 0 to 30 & 15.4 \\
\hline $523 p$ & 9.57 & 5 & $-9 ; 6$ & -1.6 & 0 to 30 & 15.4 \\
\hline $524 p$ & 10.005 & 4 & $-9 ; 6$ & -1.6 & 0 to 30 & 15.4 \\
\hline $526 \mathrm{p}$ & 10.788 & 4 & $-9 ; 6$ & -1.6 & 0 to 30 & 15.4 \\
\hline $527 \mathrm{p}$ & 11.223 & 4 & $-9 ; 6$ & -1.6 & 0 to 30 & 15.4 \\
\hline $224 p$ & 11.571 & 2 & $-14: 6$ & -1.8 & -5 to 31 & 15.3 \\
\hline$z 23 p$ & 12.006 & 3 & $-12 ; 6$ & -1.4 & -3 to 30 & 15.6 \\
\hline$z 22 p$ & 12.354 & 5 & $-12 ; 5$ & -2.6 & -3 to 29 & 14.9 \\
\hline $221 \mathrm{p}$ & 12.702 & 6 & $-9 ; 4$ & -2.5 & 6 to 28 & 14.9 \\
\hline $220 \mathrm{p}$ & 13.18 & 3 & $-14 ; 5$ & -3 & -5 to 30 & 14.5 \\
\hline $215 p$ & 15.008 & 4 & $-12 ; 5$ & -2.6 & -3 to 29 & 14.9 \\
\hline$z 14 p$ & 15.356 & 6 & $-11 ; 5$ & -2.2 & -2 to 29 & 15.2 \\
\hline$z 13 p$ & 15.704 & 4 & $-9 ; 6$ & -2.1 & 6 to 30 & 14.7 \\
\hline $212 \mathrm{p}$ & 15.878 & 4 & $-9 ; 6$ & -2.1 & 6 to 30 & 14.7 \\
\hline $211 p$ & 16.269 & 2 & $-14 ; 6$ & -1.8 & -5 to 31 & 15.3 \\
\hline $\mathrm{q} 06 \mathrm{p}$ & 16.704 & 5 & $-9 ; 6$ & -1.6 & 0 to 30 & 15.4 \\
\hline
\end{tabular}

Note. Estimated values of Tmin and Tmax have been corrected with the respective equations of the linear regressions calculated for both clusters of modern assemblages. These corrective equations are not applied to margin values which are not calculated with the median as estimated values. 